\title{
The Nursing Shortage Impact on Job Outcome (The Case in Sri Lanka)
}

\section{- Kumari Shammika Senani Mudihanselage Hellerawa, De Alwis Chamaru Adambarage}

\begin{abstract}
The nursing shortage is a common problem throughout the world. Nurses form the largest proportion of the healthcare system and play a significant role in providing direct patient care. Considering the importance of the role of nurses in the healthcare system, it is important to investigate how nursing shortage effects the quality of patient care, nurses' job satisfaction and their work stress. A study was conducted to investigate the correlation between these at the Polonnaruwa District General Hospital in Sri Lanka with a random sample of nurses) working in the hospital and using a self-administered questionnaire. This study uses an explanatory research design. The statistical analysis confirmed a positive relationship between nurse shortage and workload. It also shows a significant positive relationship between workload and the quality of patient care. Furthermore, a negative relationship was observed between workload and the quality of patient care. In addition, this study calculates the mean effect of emotional intelligence of these factors, and a significant correlation is found between emotional intelligence and workload as well as work stress. There is a firm evidence that in Sri Lanka, nursing shortage influences the workload of the employee, finally affecting the quality of patient care. In addition, the study recognized the capability of nurses to manage their emotions as well as emotions of others, which has increased their tolerance to control psychological stress in performing their duty. This study confirms that nurse's emotional intelligence act as a partial moderating variable for job outcomes of nurses.
\end{abstract}

Keywords: Patient care, Job satisfaction, Work. Stress, Emotional Intelligence, Workload and Shortage of Nurses JEL Classification: 015

\section{INTRODUCTION}

Nurses are the "backbone" of any healthcare system and their workload is multifaceted and very complex. However, there is a nursing shortage as can be seen all over the world (IOM, 2011, “The Global Shortage of Registered Nurses", 2013, "Nursing Shortage”, 2014). It is having an adverse impact on health systems around the world (Oulton, 2006). The Nursing Shortage can be defined as an overarching imbalance of supplying and demand attributed to demographics, qualifications, availability and willingness to do the work (Kimball \& O’ Nell, 2002). However, generally, when the number of nurses is not enough to provide high quality of care, it can be defined as a Shortage of Nurses (SN) (Toh et al., 2012). However, as per Birch et al. (2003) administrators fail to determine the quantity of nurses needed to provide high quality of care. Further, in economic terms, SN emerges when there are an insufficient number of nurses to provide the best quality standards and no funds to facilitate additional positions. Thus, defining SN is dif- 
ficult and complex. Nurses in countries with distinctly different healthcare systems report similar shortcomings in their work environments and the quality of hospital care. The widespread nursing shortage and nurses' high turnover have become a global issue ("The Global Shortage of Registered Nurses", 2013). The SN in hospitals and their consequences, particularly uneven quality of care, have become commonplace. Douglas (2010) suggests that Healthcare administrators need to collaborate in order to develop a viable and sustainable formula for safe staffing.

Nursing workload measures can be categorized into four levels: (1) unit level, (2) job level, (3) patient level, and (4) situation level (Carayon \& Gurses, 2005). The situation and patient-level workloads are embedded in the job-level workload, and the job-level workload is embedded in the unit-level workload. In a clinical unit, for example, numerous nursing tasks need to be performed by a group of nurses during a specific shift (unit-level workload). The type and amount of workload of nurses is partly determined by the type of unit and specialty (e.g., intensive care unit [ICU] nurse versus general floor nurse), which is the job-level workload. When performing their job, nurses encounter various situations and patients, which are determinants of the situation- and patient-level workloads (Carayon \& Gurses, 2005).

"Nursing workload is largely a function of the composite of the patients' individual health status, particularly with respect to functioning status, individual need for nursing care, and severity of symptoms" (Mueller et al., 2010). According to Hurst (2002) several criteria are available to define whether the scale and composition of nurse staffing are adequate to meeting the needs of patients and staff. In general, these criteria include factors like as "level of education, number of beds, Size of the word, acute versus chronic status of patients, the time required for individual nursing interventions and bed occupancy". (Mueller et al., 2010). "Nursing workload is also influenced by the amount of time patients spend on nursing wards, length of ward or hospital stay. Shorter length of stay compresses nursing work" (Duffield et al., 2009). However a majority of the studies on nursing workload and patient safety used nurse-patient ratio as the measure of nursing workload. According to research on workload in human factors engineering, it is well known that workload is a complex construct, more complex than the measure of nurse-patient ratio (Carayon \& Gurses, 2005). The increased turnover of patients intensifies the nursing workload further (Needleman, 2011). Admission and discharge of patients means extra documentation, general nursing and organizational duties, thereby increasing nursing workload (Weydt, 2009). The movement of patients within wards is also a factor in nursing workload, and one that is harder to quantify. Nursing workload can be further increased by nurses needing to accompany patients for investigations in other departments such as CT or MRI scans. Each new admission, transfer, or discharge, requires documentation, orientation, clinical assessment and management review, and other tasks associated with the patient will cause to increase workload.

Previous research conducted in different countries provides strong evidence that high nursing workloads at the unit level have a negative impact on patient outcomes (Lang et al., 2004, Neill, 2011). As per Buerhaus et al., (2005) more than $75 \%$ of registered nurses believe the nursing shortage presents a major problem for the quality of their work life, the quality of patient care, and the amount of time nurses can spend with patients. Further According to Buerhaus et al. 
(2005) nurses see the shortage in the future as a catalyst for increasing stress on nurses (98\%), lowering patient care quality (93\%) and causing nurses to leave the profession (93\%).

When patient needs vary significantly, staffing is more difficult to predict and can result in an increased workload for nurses because staffing may fail to match patient needs. As per Berry and Curry (2012) unequivocal nursing overload negatively affects patient outcomes. There is a significant evidence indicating that improved nurse staffing and hours of work reduce medication errors (Holden et al., 2011). According to Thungjaroenku et al. (2007) a proper nursing staffing can reduce patients' length of stay. One study shows that the number of times a nurse observes and assesses a patient in a day directly influences patient health outcomes (Shever, 2011). In addition to that, improving nursing staffing reduces the incidence of readmission (Bobay et al., 2011), Further, according to O'Connor et al. (2012) there is a significant relationship can be identified between nursing workload, quality of nursing work life, and patient satisfaction.

Buerhaus et al. (2005) define 'Job satisfaction is the nurses' as reported experience of their satisfaction with their present job. It is an important component of nurses' lives that can impact on patient safety, productivity and performance, quality of care, retention and turnover, commitment to the organization and the profession. Nurses' job satisfaction and levels of burn-out are especially important in the current context of nurse shortages. As per the study conducted by Berry and Curry in Canada in 2012, $58 \%$ of nurses dissatisfied with inadequate staffing and according to Bakker et al. (2010) majority of nurses have intention to leave form current position due to shortage of nurses.

According to Manktelow (2005) stress is considered as a cluster of related experiences, pathways, responses and outcomes caused by a range of different events or circumstances that affect respective individuals differently. Callaghan et al. (2000) define stress as a reaction to stressful situations at work that leads to a physiological response manifested by psychosomatic symptoms such as hypertension and headache'. High responsibility upon patients is of utmost importance, as if not existing, may even cost their life. Moreover, it is one of the most stressful factors within a healthcare organization; as any other stressor usually moderates staff's job satisfaction and creates turnover intentions (Kooker et al., 2007). Occupational or work-related stress has a direct effect on all nursing members of the work force, might it be of long, short or intermediate duration, or a once off experience (Weyers et al., 2006).

High workload is a key job stressor of nurses in a variety of care settings, such as ICUs (Carayon \& Gurses, 2005). A heavy nursing workload can lead to distress (e.g., cynicism, anger, and emotional exhaustion) (Greenglass et al., 2003). Nurses experiencing stress and burnout may not be able to perform efficiently and effectively because their physical and cognitive resources may be reduced; this inferior performance may affect Patient Care (PC) and its safety (Greenglass, 2003). Globally, the nursing work environment and subsequently the nursing workload, has changed considerably over the past few years.

The literature is extensive on the effects of the work environment on nurse's stress levels, collaborative practice, workload, job conflict, and job satisfaction and anticipated turnover. The effects of work-related stress are low job satisfaction, high turnover, and poor patient outcomes, resulting in large numbers of nurses leaving the profession entirely (Stichler, 2009). 
In nursing, interaction between nurse and patient is vital for the nursing practice (Bakr \& Saffan, 2012). This interaction is a complex process that involves nurse perception, understanding of the patient emotions and utilization of the perceptions to manage patient situations towards the goal of effective patient care. Further, this has been recognized as an influential factor in both individual performance and organizational performance in nursing practice that might be related to retention of nurses and patient/client outcomes (Kooker et al., 2007).

Emotional Intelligence (EI) is defined as a type of social intelligence that involves the ability to monitor one's own and others' emotions, to discriminate among them, and to use the information to guide one's thinking and actions (Bakr \& Saffan, 2012)”. According to McQueen (2003) EI has four main components, namely, the ability to, perceive emotions; utilize these emotional perceptions to accomplish various activities or tasks; understand emotional variations; and manage emotions to achieve goals. Further, EI can be viewed in two dimensions: first, the nurse's perception and understanding of the patient's emotions, second the nurse's utilization of these perceptions to achieve the goal of managing complex situations towards quality patient care (Bakr \& Saffan, 2012). Therefore, it seems a relevant concept in healthcare, when it is considered important for practitioners to understand patients' perspectives and for nursing leaders to engage in relationships that will facilitate successful management.

\section{Healthcare System and Nursing Shortage in Sri Lanka}

Sri Lanka has a free healthcare system that offers a diversity of services based on indigenous and Western medicine. The health services are delivered through an extensive network of primaryto-tertiary level community centers, hospitals, and dispensaries (Jayasekara \& Schultz, 2007). It is acknowledged that the health services offered have helped the country to achieve a relatively high health status despite a relatively low level of annual expenditure (Tan et al., 2008). The Sri Lankan healthcare system is experiencing major changes, notably in its levels of quality and safety in healthcare systems, within its limited resources. In the recently held WHO's South East Asian Summit, the Organization stated that Sri Lanka has set an example for all other regions with its excellence in the departments of hospital administration, medical services, and patient care.

Within the Sri Lankan healthcare system, nursing has a valued presence caring for patients, preventing illness, and assisting in advancing the health status of the country (Jayasekara \& Schultz, 2007). The nurse in Sri Lanka carries out many roles including providing care to patients, administering medications ordered by the doctor, coordinating paramedical services, as well as supervising junior nursing and assistant staff members. A nurse is not able to work independently and is completely task-oriented. Nurses are often the first contact point in receiving care and in most cases the last contact a patient will come across upon discharge. Therefore, nursing is very critical to healthcare delivery. However, the nursing shortage is a growing concern in Sri Lanka. If it is assumed that retirement is reached at age 60 , it would be a safe assumption to make that $22.5 \%$ of professional nurses will retire within the next 10 years in Sri Lanka. With 10.3 $\%$ of professional nurses over the age of 60 , a percentage of $33 \%$ was added to include those nurses that might probably not be available to practice within the next 10 years. Considering this along with the fact that the government cutting back on the number of nursing student posts 
and closing down number of nursing colleges, an obvious gap in the growth of this profession is caused, which might lead to increased workload and pressure for the remaining nursing staff (SANC, 2006).

First, the demand for nurses is increasing as a result of population ageing. By the end of 2012, Sri Lankan population is 20.3 million, and over- 65 population with more healthcare needs is 1.3 million and it is expected to grow by 20 percent by 2030 (Central Bank Annual Report of Sri Lanka, 2012). Second, the supply of nurses is not adequate to meet the current demand, and the shortage is projected to grow more severe as future demand increases and nursing schools are not able to keep up with the increasing educational demand (Nanayakkara, 2013). At present Sri Lanka has a nursing workforce of 27,000 nurses island wide, however, needs a cadre of 45, (Nanayakkara, 2013) When a nursing shortage occurs, the workload increases for those who remain on the job (Baumann el al., 2001). Third, in response to the increasing healthcare costs since the 1990s, hospitals reduced their nursing staffs and implemented mandatory overtime policies to meet unexpectedly high demands, which significantly increased nursing workloads (Nanayakkara, 2013) fourth, increasing cost pressure forced healthcare organizations to reduce patient length of stay. As a result, hospital nurses today take care of patients who are sicker than in the past; therefore, their work is more intensive (Aiken et al., 1996). In addition to the higher patient acuity, work system factors and expectations also contribute to the nurses' workload. Heavy nursing workload increases burnout and job dissatisfaction, which in turn contributes to high nurse turnover (Aiken et al., 2002).

\section{PROBLEM STATEMENT}

There is a shortage of 24,000 nurses in government hospitals at present and the government says they need another nursing cadre of 48,000 to fill the gap (ColomboPage, 2012). The Ministry of Health, Sri Lanka projects that the current nursing shortage will worsen over the next year, and possibly becoming a shortage of 40,000 nurses by the end of year 2013. Over 20 million people in Sri Lanka with much needed access to healthcare resources raise two questions; (1) is the current nursing workforce enough to provide the needed care? (2) Can the already burdened healthcare system provide good, safe, quality care for patients and supportive, healthy work environments for nurses? A research conducted by Aiken et al., (2002) has demonstrated that increased morbidity and mortality for patients in acute care settings can be attributed to inadequate numbers of caregivers at the bedside. According to that, the effects of increased workload, low job satisfaction, and work-related stress on nurses can negatively effect on patient care. Therefore, it is important to assess the job outcomes of nurses to ensure that they are optimally utilized. Exploring the role of the nurse may influence and provide an understanding of the negative effects of work-related stress, job dissatisfaction, and quality of patient care, thus resulting in future retention of nurses at the bedside.

There is a significant increase in the number of patients admitted to the hospital compared to the increasing number of nursing officers. A special attention was paid to the inward admissions as 24 hour nursing care is provided for inward patients. This situation is a cause to increase nurse to patient ratio and may be a factor affecting quality of patient care. 
Nurse staffing could have a different effect in different hospital settings as well as in different nursing service units. Therefore, every health institution follows the norms for nurse staffing. The latest revision of staffing norms was in the year 2001. These norms are prepared by the nurses' trade unions and approved by the Ministry of Health and the Salaries and Cadre Commission in order to improve the quality of patient care. As per this norm total nurses demand for DGH Polonnaruwa (Study unit) is 1041. However allocated workforce is 410 making Polonnaruwa an ideal location to investigate nurse shortage. Under this background the research attempts to find whether there is a relationship between the shortage of nurses and their job outcomes in relation to quality of patient care, job satisfaction and work stress and whether Emotional Intelligence moderates the above relationships.

\section{OBJECTIVES OF THE STUDY}

The key objectives of the study are:

1. To identify whether a shortage of nurses influences to workload.

2. To recognize whether workload significantly relate to quality of patient care, nurses' job satisfaction and work stress.

3. To investigate whether Emotional Intelligence (EI) moderates the relationship between workload and quality of patient care, job satisfaction, and work stress.

\section{SIGNIFICANCE OF THE STUDY}

Nursing staff is the largest personnel component in the public health sector in Sri Lanka and one of the largest component of the healthcare service population in the World. The job outcomes affected by nurses' shortage has not yet been examined in Sri Lanka. Damayanthi et al. (2014) have given attention to study the level of job satisfaction among nurses in a government hospital in the central province, Sri Lanka. However, they did not discuss about the relationship between workload and patient care and level of stress. As such there exists a knowledge gap that how the of nurses' shortage affect their job outcomes. Therefore, there is a need to seek evidence and find ways to monitor and improve nurses' performance. There is a lack of research on EI in nursing. There is no specific research which evaluates the moderating effect of EI on the relationships between workload and Nursing outcomes.

Research related to the role of emotional intelligence in patient care, job satisfaction and work stress among nurses will illuminate an understanding of these phenomena within the context of the current nursing shortage. This research is unique and significant because the areas it addresses have not been extensively studied in nursing, and it provides substantive data for professional nurses, nurse educators, and nurse administrators. Within nursing, little is known about the nurses' internal abilities (e.g., emotional intelligence) that may affect patient care, satisfaction and stress. This research intends to initiate this knowledge gap. 


\section{METHODOLOGY}

\subsection{Conceptual Framework and Variables}

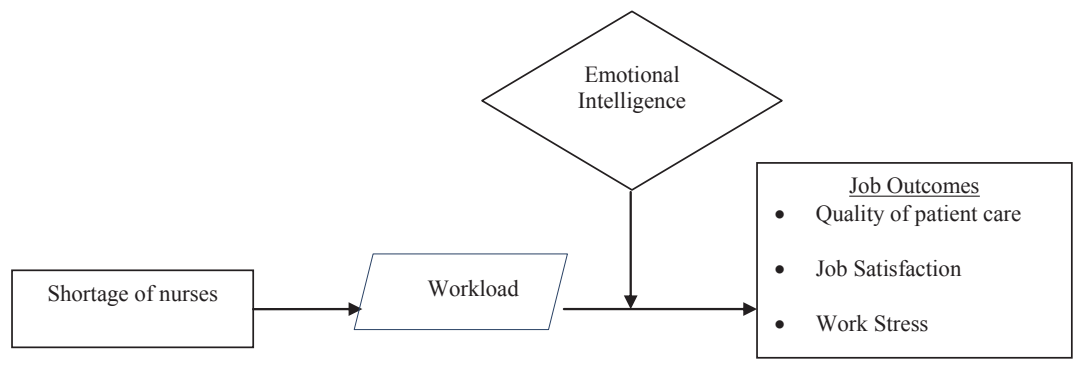

Fig. 1 - Conceptual Framework.

The following conceptual framework was developed to identify the relationships, if any, and the impact among the related variables of the research. The following operational definitions of the study variables were developed by the researcher and used in this study.

Tab. 1- Operational Definition of the Variables

\begin{tabular}{|l|l|}
\hline Variable & Definition \\
\hline Nurses' Shortage & $\begin{array}{l}\text { The number of nurses is not enough to provide high quality of } \\
\text { care as compared to the professional standard }\end{array}$ \\
\hline Quality of Patient Care & $\begin{array}{l}\text { Delivering healthcare that fulfills the expressed or implied } \\
\text { requirements of a patient }\end{array}$ \\
\hline Job Satisfaction & $\begin{array}{l}\text { The degree to which individual feel positive or negative about } \\
\text { their jobs }\end{array}$ \\
\hline Work Stress & $\begin{array}{l}\text { The response people may experience when presented with } \\
\text { work demands and pressures that are not matched to their } \\
\text { knowledge and abilities and which challenge their ability to } \\
\text { cope }\end{array}$ \\
\hline Emotional Intelligence & $\begin{array}{l}\text { The ability or skill of an individual to understand and influ- } \\
\text { ence the emotions within themselves and those around them. }\end{array}$ \\
\hline
\end{tabular}

Source: Researchers developed based on literature survey

\subsection{Hypotheses of the Study}

Based on the above conceptual framework, the following hypotheses were developed.

Objective 1: To identify whether shortage of nurses influence the workload

Hypothesis 1: Relationship between shortage of nurses and workload 
Alternative hypothesis $\left(\mathrm{H}_{1 \mathrm{a}}\right)$ - There is a positive relationship between shortage of nurses $(\mu \mathrm{NS})$ and workload $(\mu \mathrm{WL})$

$$
\begin{aligned}
& \mathrm{H}_{1}: \mu \mathrm{NS} \neq \mu \mathrm{WL} \\
& \operatorname{Corr}(\mu \mathrm{NS}, \mu \mathrm{WL})>0
\end{aligned}
$$

Objective 2: To investigate whether workload significantly relate to quality of patient care, nurses' job satisfaction and work stress.

\section{Hypothesis 2: Relationship between workload and quality of patient care}

Alternative hypothesis $\left(\mathrm{H}_{22}\right)$ - There is a negative relationship between workload ( $\left.\mu \mathrm{WL}\right)$ and quality of patient care $(\mu \mathrm{PC})$

$$
\begin{aligned}
& \mathrm{H}_{2}: \mu \mathrm{WL} \neq \mu \mathrm{PC} \\
& \operatorname{Corr}(\mu \mathrm{WL}, \mu \mathrm{PC})<0
\end{aligned}
$$

\section{Hypothesis 3: Relationship between workload and nurses' job satisfaction}

Alternative hypothesis $\left(\mathrm{H}_{32}\right)$ - There is a negative relationship between workload ( $\left.\mu \mathrm{WL}\right)$ and nurses' job satisfaction ( $\mu \mathrm{JS})$

$$
\begin{aligned}
& \mathrm{H}_{3}: \mu \mathrm{WL} \neq \mu \mathrm{JS} \\
& \operatorname{Corr}(\mu \mathrm{WL}, \mu \mathrm{J} S)<0
\end{aligned}
$$

\section{Hypothesis 4: Relationship between workload and work stress}

Alternative hypothesis $\left(\mathrm{H}_{42}\right)$ - There is a positive relationship between workload $(\mu \mathrm{WL})$ and work stress $(\mu \mathrm{WS})$

$$
\begin{aligned}
& \mathrm{H}_{3}: \mu \mathrm{WL} \neq \mu \mathrm{WS} \\
& \operatorname{Corr}(\mu \mathrm{WL}, \mu \mathrm{WS})>0
\end{aligned}
$$

Objective 3: To investigate whether EI moderates the relationship between workload and quality of patient care, job satisfaction, and work stress.

Hypothesis 5: Moderate effect to the relationship between workload and quality of patient care

Alternative hypothesis $\left(\mathrm{H}_{5 \mathrm{a}}\right)$ - EI $(\mu \mathrm{EI})$ significantly moderates the relationship between workload $(\mu \mathrm{WL})$ and quality of patient care $(\mu \mathrm{PC})$

$$
\mu \mathrm{PC}=\mathrm{C} 0+\mathrm{C} 1 \mu \mathrm{WL}+\mathrm{C} 2 \mu \mathrm{EI}+\mathrm{C} 3(\mu \mathrm{WL} \mu \mathrm{EI}) \quad \mathrm{C} 0, \mathrm{C} 1, \mathrm{C} 2, \mathrm{C} 3 \text { are constants. } \mathrm{C} 3 \neq 0
$$

Hypothesis 6: Moderate effect to the relationship between workload and nurses' job satisfaction

Alternative hypothesis $\left(\mathrm{H}_{62}\right)$ - EI $(\mu \mathrm{EI})$ significantly moderates the relationship between workload $(\mu \mathrm{WL})$ and job satisfaction $(\mu \mathrm{JS})$

$$
\mu \mathrm{JS}=\mathrm{C} 0+\mathrm{C} 1 \mu \mathrm{WL}+\mathrm{C} 2 \mu \mathrm{EI}+\mathrm{C} 3(\mu \mathrm{WL} \mu \mathrm{EI}) \quad \mathrm{C} 0, \mathrm{C} 1, \mathrm{C} 2, \mathrm{C} 3 \text { are constants. } \mathrm{C} 3 \neq 0
$$

Hypothesis 7: Moderate effect to the relationship between workload and work stress

Alternative hypothesis $\left(\mathrm{H}_{72}\right)$ - EI $(\mu \mathrm{EI})$ significantly moderates the relationship between workload ( $\mu \mathrm{WL})$ and work stress ( $\mu \mathrm{WS})$

$$
\mu \mathrm{WS}=\mathrm{C} 0+\mathrm{C} 1 \mu \mathrm{WL}+\mathrm{C} 2 \mu \mathrm{EI}+\mathrm{C} 3(\mu \mathrm{WL} \mu \mathrm{EI}) \quad \mathrm{C} 0, \mathrm{C} 1, \mathrm{C} 2, \mathrm{C} 3 \text { are constants. } \mathrm{C} 3 \neq 0
$$




\subsection{Population, Sample and Sample Selection Method}

The District General Hospital of Polonnaruwa has a total of 23 wards which equipped with 750 patients' beds, 09 theatre beds and 10 ICU beds. Among them, 380 employees are Grade II A \& II B nurses. There are 32 nursing administrators. The target population of this study comprises with the total nursing staff $(\mathrm{N}=412)$ and inward patients of the hospital at the time of the study. Using simple random sampling method 100 nurses were selected from the nursing category of Grade I and II. The process of selecting the sample was involved with the sampling frame. The sampling frame is a representation of all the elements in the population from which the sample is drawn (Sekaran \& Bougie, 2011). The availability of a frame simplifies the sample selection process. The choice of a frame is often based on convenience and accessibility. The most convenient frames are often in the form of computer data files. In this study, the payroll of the hospital served as the sampling frame from which the nursing officers were chosen.

\subsection{Data Collection Design}

This tool was structured questionnaire developed by the researchers based on literature review to assess nurse's workload, stress, satisfaction, patient care and emotional intelligence. This questionnaire was basically divided into six sections by considering the following objectives:

Section 1: designed to collect demographic information about the respondent. The first section, comprising of questions 1 to 11 required personal information with regards to current position, number of service years, age, gender, marital status and the number of dependents living with them.

Section 2: Questions 12 to 21 were included to determine the job satisfaction level of nurses. Respondents were required to make a choice from the job satisfaction elements listed. Response alternatives of very dissatisfied, dissatisfied, neutral, satisfied and very satisfied were applicable to all these 10 questions.

Section 3: Questions 22 to 31 were about the work stress level of nurses. Respondents were requested to select one choice by circling the number on the scale. The Likert scale with five response alternatives of no pressure, some pressure, and moderate pressure, more than average and extreme pressure was used to measure opinion, reaction and attitude in relation to the statement given.

Section 4: This section requested respondents to make choices on what is applicable to them in relation to their ability to experience the emotions of others. A rating scale with five response alternatives of strongly disagree, disagree, uncertain, agree and strongly agree was applied to questions 32 to 40 .

Section 5: Questions 41 to 49 attempted to determine the workload level of nurses. Respondents were requested to make a choice. Likert scale was used to measure workload level of nurses. The scale consisted with five response alternatives of strongly disagree, disagree, uncertain, agree and strongly agree for all question items.

Section 6: The last section of the Questionnaire comprising of questions 50 to 59 determines the view of nurses' satisfaction with their job. Likert scale with five response alternatives of strongly disagree, disagree, uncertain, agree and strongly agree was applied to all 10 questions in this section. 
Further information about above self-developed scales are shown in the Tab 2.

Tab. 2 - Self developed scales to measure the variables of the study

\begin{tabular}{|c|c|c|c|}
\hline Variable & Indicators & $\begin{array}{l}\text { Number of } \\
\text { statements }\end{array}$ & $\begin{array}{l}\text { Type of meas- } \\
\text { urement }\end{array}$ \\
\hline Workload & $\begin{array}{l}\text { Shift Duration } \\
\text { Overtime (Mandatory and Voluntary) } \\
\text { Busyness of the Ward } \\
\text { Floating to Nursing Units }\end{array}$ & 8 & \multirow{5}{*}{$\begin{array}{l}\text { 5-point Likert- } \\
\text { type State- } \\
\text { ments }\end{array}$} \\
\hline $\begin{array}{l}\text { Quality of Patient } \\
\text { Care }\end{array}$ & $\begin{array}{l}\text { Communicating with Nurse } \\
\text { Respect for patient values } \\
\text { Showing attention to the patient } \\
\text { Nurses' Competence }\end{array}$ & 10 & \\
\hline Job Satisfaction & $\begin{array}{l}\text { Nature of the work } \\
\text { Work environment } \\
\text { Interpersonal relations } \\
\text { Career advancement }\end{array}$ & 10 & \\
\hline Work Stress & $\begin{array}{l}\text { Nature of the work } \\
\text { Dealing with the staff } \\
\text { Work environment } \\
\text { Required knowledge and skills }\end{array}$ & 10 & \\
\hline $\begin{array}{l}\text { Emotional Intel- } \\
\text { ligence }\end{array}$ & $\begin{array}{l}\text { Ability to work under pressure } \\
\text { Ability to manage stress } \\
\text { Ability to Control Own Impulses } \\
\text { Adaptation to Environment } \\
\text { Problem Solving Skills }\end{array}$ & 8 & \\
\hline
\end{tabular}

Source: Researchers developed based on literature survey

Initial contact was made with the chief special grade nursing officer and grade I nursing officers to avoid the possibility of non-return and incomplete questionnaires. A questionnaire was translated into Sinhala language and printed before delivering. Questionnaires were delivered personally by the researchers with the help of one of special grade nursing officers to the nurse in charge of each ward or unit. During these visits, the aim and the importance of the study and questionnaire return dates were explained. Respondents were informed that their participation is voluntary and that they have the right to withdraw from the study at any time if they wish. When distributing questionnaires for nurses, anonymity and confidentiality were promised and ensured by providing a white color return envelope and a cover letter. The respondents were 
asked not to write their names on the envelope or questionnaire. The cover letter explained the instructions for completing and return of the questionnaire. Two collecting boxes were kept in the two main matron's offices to collect the completed questionnaires from nurses.

Secondary data were collected for assessing shortage of nurses and the workload level of nurses. The data were acquired through the duty rosters of nurses, over time registers, days-off registers and other reports and circulars of the hospital. In addition to that secondary data also collected from recorded or published information external to the organization and through the internet. After permission was received from the relevant authorities, a pilot study was carried out with nursing officers. They were asked to give constructive feedback with regard to clarity of questions and time necessary to complete the questionnaires.

\subsection{Reliability and Validity}

In this study, the content validity was used to assess to validate the instruments by including all the key concepts relevant to the research topic. Content validity of instruments in this study is based on a comprehensive investigation on a relevant literature review conducted by the researchers. The questions were formulated according to the means of assessing the adequacy, appropriateness and relevancy to the components of the conceptual framework. The Cronbach's Alpha test was used to test the internal consistency of the instruments. As a rule of thumb lenient cut-off of .60 $(\alpha=.60)$ is common in exploratory research. In general, reliabilities that scored less than $.60(\alpha=.60)$ are considered poor; more than.80 $(\alpha=.80)$ are considered good. The alpha should be at least .60 ( $\alpha=.60)$ or higher to retain an item in an adequate scale (Sekaran \& Bougie, 2009). Prior to performing statistical analysis on the hypothesis, reliability tests were conducted using IBM SPSS English version 21.0 to confirm the internal consistency. All constructs were found highly reliable as Cronbach's alpha values were above 0.8 as shown in the tab. 3 .

Tab. 3 - Reliability Analysis

\begin{tabular}{|l|c|}
\hline Variable / Construct & $\begin{array}{l}\text { Cronbach's } \\
\text { Alpha }\end{array}$ \\
\hline Job Satisfaction & .901 \\
\hline Workload & .847 \\
\hline Work Stress & .920 \\
\hline Emotional Intelligence & .934 \\
\hline Quality of Patient Care & .813 \\
\hline
\end{tabular}

Source: Pilot survey

\section{FINDINGS AND DISCUSSION}

\subsection{Descriptive Statistics}

Hundred nursing officers represented to the sample from eight selected wards and units of District General Hospital Polonnaruwa. However, only 93 nursing officers have returned their com- 
pleted questionnaires. The majority of 77 respondents were female nurses $(82.8 \%)$ and male nurses were $17.2 \%(\mathrm{~N}=16)$. With regards to the employment grade and position it was revealed that the respondents consisted with $45.2 \%$ of Grade II-A nurses, $43 \%$ of Grade II-B nurses and a few number of Grade I nurses $(11.8 \%)$

\subsection{Nurses' Shortage}

According to data evaluated by nursing administrators at the District General Hospital Polonnaruwa, it was expected that at least 175 another nursing officers required for maintaining total nursing care by the year 2014. There were 410 nurses working and among them 65 nurses were on maternity leave. Another 34 of them have gone for the special training. In addition, one nurse has taken overseas leave for a two year period. Nurses are working round the clock throughout the day and they are working two numbers of six hour day shifts and 12 hour night shift (including 2 hour rest). According to the calculation based on nursing norms, number of nurses' requirement for a day is 390 . In the actual situation, only 326 nurses to deliver total nursing care in all wards and units at the hospital. Considering all these, it can be concluded that there is a severe nursing shortage in the Hospital.

\subsection{Workload}

Nursing workload is mainly influenced by the shortage of nurses and the number of patients staying in the ward. In Sri Lankan healthcare setting, a nursing ward is where a large number of patients requiring care and lack of resources to provide care with inadequate number of nurses. Nurses are midst of the system that requires them to work hard. Normally, hospital wards are overcrowded with large number of patients, bystanders and healthcare staff (De Silva, 2000), It looks very busy, a chaotic and demanding environment for nurses to work in. Comparing large patient numbers do not increase the number of nurses and the roster remains the same. Therefore, the study results showed that the considerable number of nurses continued their duty to next shift. 35 nurses $(35.6 \%)$ indicated that their duty shift was often extended within the last month. This situation led nurses to do more overtime to make up minimum nurse workforce numbers. Considering the overtime done by nurses, $66.67 \%(\mathrm{~N}=62)$ of nurses have done more voluntary overtime hours compared to the mandatory overtime ( $\mathrm{N}=42,45.16 \%$ ).

The increased workload of nurses leads to high possibility in nursing errors and delays. It was evident in this study that, increased workload has influenced both tasks delayed and tasks not completed $(\mathrm{N}=30,32.26 \%)$. The working situation in the ward highlighted that the nurses have limited time to interact with their patients. Because of the routine nursing tasks like medication, injections, referrals, blood transfusion that nurses have to undertake, they have not enough time to talk with patients. The significant number of nurses $(\mathrm{N}=61,65.6 \%)$ reported that they have less time available to deliver care, because they have to complete non-patient activities such as maintaining ward statistics, dietary, nursing administration, housekeeping during the shift.

The study reveals that the several wards and units at the hospital have a steady increase in workload. According to the research findings, the highest amount of work load reported in gynecology and obstetrics wards while less amount of work load reported in pediatrics wards. Further surgical and medical wards indicated same amount of workload 


\subsection{Hypotheses Testing}

$\mathrm{H}_{1 \mathrm{a}}$ - There is a positive relationship between shortage of nurses ( $\mu$ NS) and workload ( $\mu \mathrm{WL}$ )

$$
\begin{gathered}
\mathrm{H}_{1}: \mu \mathrm{NS} \neq \mu \mathrm{WL} \\
\operatorname{Corr}(\mu \mathrm{NS}, \mu \mathrm{WL})>0
\end{gathered}
$$

The Pearson Product Moment Correlation Coefficient was performed to identify the relationship between nurses' shortage and workload level of nurses. Nurses' shortage ( $M=3.29$, Std. D $=0.49)$ found significantly correlated with workload level of nurses $(\mathrm{M}=3.17$, Std. $\mathrm{D}=0.58)$, $\mathrm{p}=0.046$ at the $5 \%$ level. According to the research findings, there is a positive relationship between the two variables. Therefore, alternative hypothesis $\left(\mathrm{H}_{12}\right)$ was accepted. In other words, there is a positive relationship between shortage of Nurses and workload.

$\mathrm{H}_{2 \mathrm{a}}$ - There is a negative relationship between workload ( $\mu \mathrm{WL}$ ) and quality of patient care $(\mu \mathrm{PC})$

$$
\begin{gathered}
\mathrm{H}_{2}: \mu \mathrm{WL} \neq \mu \mathrm{PC} \\
\operatorname{Corr}(\mu \mathrm{WL}, \mu \mathrm{PC})<0
\end{gathered}
$$

The Pearson Product Moment Correlation Coefficient was applied to measure the relationship between workload level of nurses and quality of patient care. Workload level of nurses $(\mathrm{M}=3.17$, Std. $\mathrm{D}=0.57)$ found significantly correlated with quality of patient care $(\mathrm{M}=3.29$, Std. $\mathrm{D}=0.26)$, $\mathrm{p}=0.049$. Correlation is significant at the 0.05 level (1-tailed). The negative correlation of workload level and the quality of patient care was evidenced to accept the alternative hypothesis $\left(\mathrm{H}_{2 \mathrm{a}}\right)$.

\section{$H_{3 a}$ - There is a negative relationship between workload ( $\left.\mu \mathrm{WL}\right)$ and nurses' job satisfac- tion $(\mu \mathrm{JS})$}

$$
\begin{gathered}
\mathrm{H}_{3}: \mu \mathrm{WL} \neq \mu \mathrm{JS} \\
\operatorname{Corr}(\mu \mathrm{WL}, \mu \mathrm{JS})<0
\end{gathered}
$$

The Pearson Product Moment Correlation Coefficient was performed to identify the relationship between workload level and job satisfaction of nurses. Workload level of nurses $(\mathrm{M}=3.17$, Std. $\mathrm{D}=0.58)$ found negatively correlated with job satisfaction $(\mathrm{M}=2.99$, Std. $\mathrm{D}=0.39), \mathrm{p}=$ 0.180. But there was a non-significant correlation at the 0.05 level (1-tailed). The p-value of 0.180 denoted not to reject the null hypothesis $\left(\mathrm{H}_{3 \mathrm{n}}\right)$. In other words, there is no relationship between workload and job satisfaction.

$\mathrm{H}_{4 \mathrm{a}}$ - There is a positive relationship between workload ( $\mu \mathrm{WL}$ ) and work stress ( $\mu$ WS $)$

$$
\begin{gathered}
\mathrm{H}_{3}: \mu \mathrm{WL} \neq \mu \mathrm{WS} \\
\operatorname{Corr}(\mu \mathrm{WL}, \mu \mathrm{WS})>0
\end{gathered}
$$

According to the research findings, it is evident that there was a non-significant positive correlation $(p=0.179)$ between workload level and work stress of nurses. The following descriptive statistics measured by Pearson Product Moment Correlation Coefficient presented a workload level of nurses $(M=3.17$, Std. $\mathrm{D}=0.58)$ with work stress $(\mathrm{M}=3.31$, Std. $\mathrm{D}=0.48)$. Therefore the alternative hypothesis $\left(\mathrm{H}_{4 \mathrm{a}}\right)$ was rejected and the null hypothesis was accepted $\left(\mathrm{H}_{4 \mathrm{n}}\right)$. 
Tab. 2 - Correlation between Nurses' Workload and Selected Variables

\begin{tabular}{|c|c|c|c|c|c|c|}
\hline $\begin{array}{c}\text { Hypothesis } \\
\text { No }\end{array}$ & Relationship & Correlation & M & SD & N & Sig. \\
\hline $\mathrm{H}_{2 \mathrm{a}}$ & $\begin{array}{c}\text { with quality of } \\
\text { patient care }\end{array}$ & $-0.236^{*}$ & 3.29 & 0.26 & 50 & 0.049 \\
\hline $\mathrm{H}_{3 \mathrm{a}}$ & $\begin{array}{c}\text { with job satis- } \\
\text { faction }\end{array}$ & -0.096 & 2.99 & 0.39 & 93 & 0.180 \\
\hline $\mathrm{H}_{4 \mathrm{a}}$ & with work stress & 0.141 & 3.31 & 0.48 & 93 & 0.179 \\
\hline
\end{tabular}

* Correlation is significant at the 0.05 level

Alternative hypothesis $\left(\mathrm{H}_{5 a}\right)$ - EI $(\mu \mathrm{EI})$ significantly moderate the relationship between workload $(\mu \mathrm{WL})$ and quality of patient care $(\mu \mathrm{PC})$

$$
\mu \mathrm{PC}=\mathrm{C} 0+\mathrm{C} 1 \mu \mathrm{WL}+\mathrm{C} 2 \mu \mathrm{EI}+\mathrm{C} 3(\mu \mathrm{WL} \mu \mathrm{EI}) \quad \mathrm{C} 0, \mathrm{C} 1, \mathrm{C} 2, \mathrm{C} 3 \text { are constants. } \mathrm{C} 3 \neq 0
$$

The Moderated Multiple Regression model was run to find whether the association between workload and quality of patient care moderates with EI. Results indicated that EI $(b=.038, \mathrm{SEb}$ $=.102, \beta=.053, \mathrm{p}>.05)$ and the interaction between workload to EI $(\mathrm{b}=.142, \mathrm{SEb}=.164, \beta=$ $.121, \mathrm{p}>.05)$ both were not associated with quality of patient care. But workload ( $\mathrm{b}=.140, \mathrm{SEb}$ $=.060, \beta=.330, \mathrm{p}<.05)$ was positively significant $(\mathrm{p}=.023)$. These results indicated that the relationship between workload and quality of patient care was not moderated by EI. Therefore, alternative hypothesis (H5a) was rejected and null hypothesis (H5n) was accepted.

Simple slopes for the association between workload and quality of patient care were tested for low (-1 SD below the mean), moderate (mean) and high (+1 SD above the mean) levels of EI. All simple slope tests revealed a positive association between workload and quality of patient care. But it showed a significant positive relationship for moderate level of EI (Fig. 2).

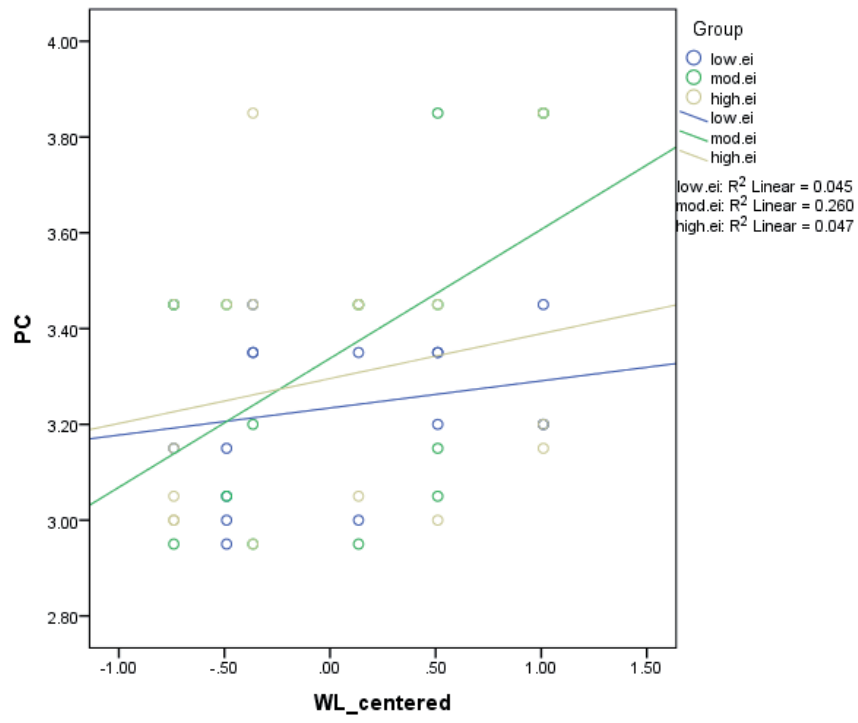

Fig. 2 - The Interaction of EI on Workload and Quality of Patient Care. Source: Survey Data 
Alternative hypothesis $\left(\mathrm{H}_{6 \mathrm{a}}\right)$ - EI $(\mu \mathrm{EI})$ significantly moderate the relationship between workload $(\mu \mathrm{WL})$ and job satisfaction ( $\mu \mathrm{JS})$

$$
\mu \mathrm{JS}=\mathrm{C} 0+\mathrm{C} 1 \mu \mathrm{WL}+\mathrm{C} 2 \mu \mathrm{EI}+\mathrm{C} 3(\mu \mathrm{WL} \mu \mathrm{EI}) \quad \mathrm{C} 0, \mathrm{C} 1, \mathrm{C} 2, \mathrm{C} 3 \text { are constants. } \mathrm{C} 3 \neq 0
$$

The Moderated Multiple Regression analysis was conducted to examine the moderate effect to the relationship between workload and quality of patient care. After centering workload and emotional level of nurses and computing the workload by EI interaction term, the two predictors and the interaction centered into a simultaneous regression model. Results indicated that EI (b $=.030, \mathrm{SEb}=.128, \beta=.025, \mathrm{p}>.05)$ and workload $(\mathrm{b}=-.038, \mathrm{SEb}=.057, \beta=-.072, \mathrm{p}>.05)$ were both not associated with job satisfaction of nurses. The interaction between workload and EI was not significant $(b=-.231, \mathrm{SEb}=.231, \beta=-.106, \mathrm{p}>.05)$, suggesting that the relationship between workload and job satisfaction does not control by EI.

According to the analyzed results alternative hypothesis $\left(\mathrm{H}_{62}\right)$ was rejected.

\section{Moderate effect of EI to the relationship between workload and work stress}

Alternative hypothesis $\left(\mathrm{H}_{7 \mathrm{a}}\right)$ - EI $(\mu \mathrm{EI})$ significantly moderate the relationship between workload ( $\mu \mathrm{WL})$ and work stress $(\mu \mathrm{WS})$

$$
\mu \mathrm{WS}=\mathrm{C} 0+\mathrm{C} 1 \mu \mathrm{WL}+\mathrm{C} 2 \mu \mathrm{EI}+\mathrm{C} 3(\mu \mathrm{WL} \mu \mathrm{EI}) \quad \mathrm{C} 0, \mathrm{C} 1, \mathrm{C} 2, \mathrm{C} 3 \text { are constants. } \mathrm{C} 3 \neq 0
$$

The Moderated Multiple Regression model was used to investigate whether the association between workload and work stress level of nurses moderates with EI. After centering workload and emotional level of nurses and computing the workload by EI interaction term, the two predictors and the interaction centered into a simultaneous regression model. Results indicated that EI $(\mathrm{b}=$ $.208, \mathrm{SEb}=.187, \beta=.133, \mathrm{p}>.05)$ and workload $(\mathrm{b}=.127, \mathrm{SEb}=.083, \beta=.155, \mathrm{p}>.05)$ were both not associated with job satisfaction of nurses. But the interaction between workload to EI was significant $(\mathrm{p}<.05)(\mathrm{b}=-.744, \mathrm{SEb}=.339, \beta=-.224, \mathrm{p}=.031)$, suggesting that relationship between workload and work stress moderated by EI. Base on this results alternative hypothesis (H7a) was accepted.

Simple slopes for the association between workload and work stress were tested for low (-1 SD below the mean), moderate (mean) and high ( $+1 \mathrm{SD}$ above the mean) levels of EI. Low and moderate simple slope tests revealed a positive non-significant association between workload and work stress level of nurses. But the workload was significantly moderated to work stress for high levels of EI (Fig. 3).

Tab. 3 - Correlation between Nurses’ EI Level and Selected Variables. Source: Survey Data

\begin{tabular}{|l|l|c|c|c|c|c|}
\hline $\begin{array}{l}\text { Hypothesis } \\
\text { No }\end{array}$ & Relationship & B & SEb & $\beta$ & $\mathrm{t}$ & Sig \\
\hline $\mathrm{H}_{5 \mathrm{a}}$ & $\begin{array}{l}\text { with workload and quality of } \\
\text { patient care }\end{array}$ & 0.142 & 0.164 & 0.121 & 0.866 & 0.391 \\
\hline $\mathrm{H}_{6 \mathrm{a}}$ & with workload and job satisfaction & -0.231 & 0.231 & -0.106 & -0.997 & 0.322 \\
\hline $\mathrm{H}_{7 \mathrm{a}}$ & with workload and work stress & -0.744 & 0.339 & -0.224 & -2.193 & $0.031^{*}$ \\
\hline
\end{tabular}

* Correlation is significant at the 0.05 level 


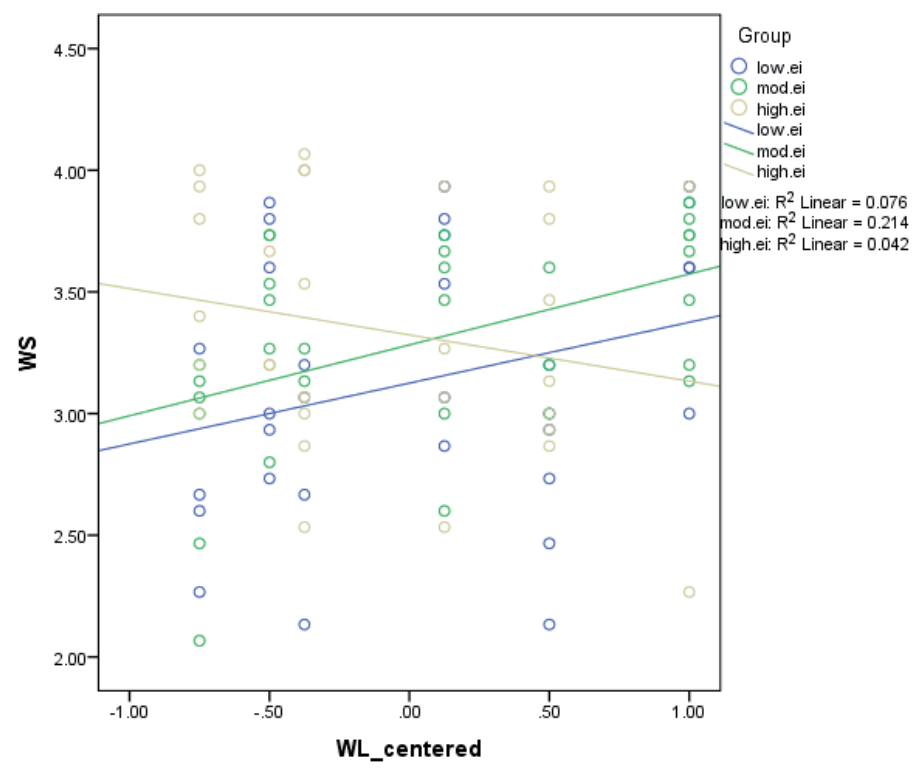

Fig. 3 - The Interaction of EI on Workload and Work Stress Level. Source: Survey Data

As per the research findings, the workload directly influences to the quality of patient care and again it confirms the research findings of Aiken et al, 2002: Goodin, 2002: Keijsers et al., 1995: Stone, et al., 2007: Toh and Devi, 2012.

Damayanthi et al (2014): Anderson and Maloney (1998): Toh et al (2012) Beaudoin \& Edgar (2003); Smith (2002) and Aiken et al. (2002) found a significant negative relationship between the workload and the job satisfaction and Goodin (2002) and Toh et al. (2012) found a negative relationship between the workload and the stress, however, this research findings do not support for those past research findings.

\section{CONCLUSION}

The research findings reveal that nurses are consistently working long over stretched shifts due to staff shortage. This study reveals the nurse's workload directly influences to the quality of patient care. However, it does not influence significantly to the level of satisfaction and level of stress. Secondly the study has examined the impact of EI upon job outcomes; quality of patient care, job satisfaction and work stress. The research findings indicated that EI had a moderate effect on the relationship between workload and work stress while it was not found to be related with job satisfaction and quality of patient care.

The administration needs to customize their strategies for the recruitment and retention of nurses. The strategies should take into consideration the specific work settings that are experiencing negative nursing outcomes (poor patient care). The strategies should also aim to train that help nurses better manage their emotions. 
A hospital is a group of healthcare professionals (primary care physicians, specialists and nurses) that work together as a team to coordinate care for patients. Nurses are mainly responsible for managing patients' health and providing care. They are set to play integral roles that include acting as care coordinators, communicators and quality improvement while providing care for patients. As a solution for nursing shortage prevailing in the country, health organizations can be reassigned the roles played by nurses only for patient-centered care. Nurses deployed for other services than direct patient care such as receptions and health education can be replaced with some other qualified personals. Many nurses are concerned that these substitutions could improve the quality of patient care. It is recommended that stress management training should be provided especially for nursing staff. The staff in management positions should emphasize the importance of interactions among nursing staff and between nurses and patients. The performance of emotional work was associated with fewer negative effects and with more positive psychological and social wellbeing for hospital nurses. Therefore the performance of emotional work should be considered to be a valuable coping strategy to be encouraged by hospital management.

\section{References}

1. Aiken, L., Clarke, S., Sloane, D., Sochalski, J., \& Hiber, J. (2002). Hospital nurse staffing, patient mortality, nurse burnout, and job satisfaction. Journal of the American Medical Association, 288(16), 1987. doi:10.1001/jama.288.16.1987

2. Aiken, L., Sochalski, J., \& Anderson, G. (1996). Downsizing the hospital nursing workforce. Health Affairs, 15, 88-92. doi:10.1377/hlthaff.15.4.88

3. Anderson, F. D., \& Maloney, J. P. (1998). A descriptive, correlational study of patient satisfaction, provider satisfaction, and provider workload at an Army medical center. Mil Med.;163(2), 90-4. DOI : 10.1111/j.1553-2712.2000.tb02050.x

4. Bakker, D., Conlon, M., Fitch, M. et al. (2010). Canadian oncology nurse work environments: part I. Nursing Leadership; 22(4), 50-68. doi:10.12927/cjnl.2010.21597

5. Baumann, A., Giovannetti, P., \& O’Brien-Pallas, L. et al. (2001). Healthcare restructuring: the impact of job change. Canadian Journal of Nursing Leadership, 14, 14-20. http://dx.doi. org/10.12927/cjnl.2001.16306

6. Beaudoin, L. E., \& Edgar, L. (2003). Hassles: Their importance to nurses' quality of work life. Nursing Economics, 21(3), 106-113.

7. Berry, L., \& Curry, P. (2012). Nursing Workload and patient care: understanding the value of nurses, the effects of excessive workload, and how nurse-patient ratios and dynamic staffing models can help (Vol 1.). Ottawa: The Canadian Federation of Nurses Unions

8. Birch, S., O’Brien-Pallas, L., Alksnis, C., Murphy, G., \& Thompson, D. (2003). Beyond demographic change in human resources planning: an extended framework and application to nursing. Journal of Health Services Research and Policy, 8, 225-9.

9. Bleich, M. R. (2011). IOM report, The future of nursing: Leading change, advancing health: Milestones and challenges in expanding nursing science. Research in Nursing \& Health, 34(3), 169-170. doi:10.1002/nur.20433 
10. Bobay, K., Yakusheva, O., \& Weiss, M. (2011). Outcomes and cost analysis of the impact of unit-level nurse staffing on post-discharge utilization. Nursing Economics, 29(2), 69-87

11. Buerhaus, P. (1997). What is the harm in imposing mandatory hospital nurse staffing regulations? Nursing Economics, 8 (4), 225-229.

12. Buerhaus, P. I., Donelan, K., Ulrich, B. T., Norman, L., \& Dittus, R. (2005). Is the shortage of hospital registered nurses getting better or worse? Findings from two recent national surveys of RNs. Nurs Econ, 23, 61-71.

13. Burnard, P. (1994). Counselling: A Guide to Practice in Nursing. Oxford: ButterworthHeinnemann.

14. Callaghan, P., Tak-Ying, S. A., \& Wyatt, P. A. (2000). Factors related to stress and coping among Chinese nurses in Hong Kong. Journal of Advanced Nursing, 31(6), 1518-1527. doi:10.1046/j.1365-2648.2000.01434.x

15. Carayon, P., \& Gurses, A. (2005). Nursing workload and patient safety in intensive care units: a human factors engineering evaluation of the literature. Intensive critical Care Nursing, 21, 284-301.

16. Central Bank Annual Report (2012). Central Bank of Sri Lanka.

17. Damayanthi, H., Wichaikhum, O., \& Chontawan, R. (2014). Predicting Factors of Job Satisfaction among Nurses in Sri Lanka. International Journal of Pharmacy \& Bioscience, 1(1), 1-7.

18. De Silva, B. S. S., \& Rolls, C. (2010). Health-care system and nursing in Sri Lanka: An ethnography study. Nursing \& Health Sciences, 12(1), 33-38. doi:10.1111/j.14422018.2009.00482.x

19. Douglas, K. (2010). Ratios: If it were only that easy. Nursing Economics, 28 (2), 119-125.

20. Duffield, C., O’Braien, L., Diers, D., Aisbett, C., Aisbett, \& Homer, C. K. (2009). Nursing Workload and Staffing: Impact on Patients and Staff. University of Technology Sidney.

21. Greenglass, E. R., Burke, R. J., \& Moore, K. A. (2003). Reactions to increased workload: effects on professional efficacy of nurses. Apply Psychology: An International Review, 52 (4), 580- 597. http://dx.doi.org/10.1111/1464-0597.00152

22. Holden, R., Scanlon, M., Patel, N., Kaushal, R., Hamilton Escoto, K., Brown, R., Alper, S., Arnold, J., Shalaby, T., Murkowski, K. \& Karsh, B. (2011). A human factors framework and study of the effect of nursing workload on patient safety and employee quality of working life. British Journal of Medicine Quality \& Safety, 20, 15-24.

23. Hurst, K. (2002). Selecting and Applying Methods for Estimating the Size and Mix of Nursing Teams. A systematic review of the literature commisioned by the Department of Health. Leeds.

24. Jayasekara, R., \& Schultz, T. (2007). Health status, trends and issues in Sri Lanka. Nurses Health science, 9(3), 228-233. http://dx.doi.org/10.1111/j.1442-2018.2007.00328.x

25. Keijsers, G. J., Schaufeli, W. B., Le Blanc, P. M., Zwerts, C., \& Miranda, D. R. (1995). Performance and burnout in intensive care units. Work \& Stress, 9(4), 513-527. doi:10.1080/ 02678379508256897 
26. Kimball, B., \& O’Neil, E. (2002). Healthcare's Human Crisis: The American Nursing Shortage.

27. Kooker, B., Shoultz, J., \& Codier, E. (2007). Identifying Emmotional Inteligence in professional nursing practice. Journal of Professional Nursing, 23(1), 30-36. http://dx.doi. org/10.1016/j.profnurs.2006.12.004

28. Manktelow, J. (2005). Mind Tools: Essential skills for an Excellent Career. London: Mind Tools Ltd.

29. McQueen, A. C. (2004). Emotional intelligence in nursing work. Journal of Advanced Nursing, 47(1), 101-108. doi:10.1111/j.1365-2648.2004.03069.x

30. Mueller, M., Lohmann, S., Strobl, R., Boldt, C., \& Grill, E. (2010). Patients' functioning as predictor of nursing workload in acute hospital units providing rehabilitation care: A multicentre cohort study. BMC Health Services Research, 10(1), 295. doi:10.1186/1472-6963-10-295

31. Nanayakara, K. (2013). Shortage Of Nurses At State Hospitals. The Sunday Leader. Retrieved June 19, 2014, from http://www.thesundayleader.lk/2013 /05/19/shortage-of-nurses-at-statehospitals/

32. Needleman, J., Buerhaus, P., Pankratz, S., Leibson, C. \& Stevens, S. (2011). Nurse staffing and inpatient hospital mortality. New England Journal of Medicine, 364(11), 1037-1045. doi:10.1056/nejmsa1001025

33. Neill D. (2011). Nursing workload and the changing healthcare environment: a review of the literature. Administrative Issues Journal, 1(2), 112- 143. doi:10.5929/2011.1.2.11

34. Nursing Inquiry, (pp. 205-212). http://dx.doi.org/10.1046/j.1440-1800.2001.00116

35. Nursing Shortage. (2014). Retrieved June 2, 2014, from http://www.aacn.nche.edu/mediarelations/fact-sheets/nursing-shortage

36. O’Connor, P., Ritchie, J., Drouin, S., \& Covell, C. (2012). Redesigning the workplace for 21st century healthcare. Healthcare Quarterly, 15(Sp), 30-35. doi:10.12927/hcq.2012.22844

37. Oulton, J. A. (2006). The Global Nursing Shortage: An Overview of Issues and Actions Policy Politics Nursing Practice, 7(3 suppl), 34S-39S. doi: 10.1177/1527154406293968

38. SANC. (2006). Where are the nurses? Nursing Update, 30 (4), 42-45.

39. Sekaran, U., \& Bougie, R. (2009). Research Methods for Business: A Skill Building Approach (Vol 5.). New Delhi: Wiley India Pvt. Ltd.

40. Shever, L. L. (2011). The impact of nursing surveillance on failure to rescue. Research and Theory for Nursing Practice: An International Journal, 25 (2), 107-126. doi:10.1891/15416577.25.2.107

41. Stichler, J. F. (2009). Creating a healthy, positive work environment: A leadership imperative. Nursing for Women's Health, 13(4), 341-346. http://dx.doi.org/10.1111/j.1751486x.2009.01445.x

42. Tan, G., Goonasekara, C., \& Curran, S. (2008). Emergency medicine in Sri lanka: The inevi table evolution to a new specialty. Emergency Medicine in Australia, 20 (1), 81-84. http://dx.doi. $\operatorname{org} / 10.1111 / j .1742-6723.2007 .01052 . x$ 
43. The Global Shortage of Registered Nurses: An Overview of Issues and Actions. (2013). Retrieved June 2, 2014, from http://www.icn.ch/publications/the-global-shortage-ofregistered-nurses-an-overview-of-issues-and-actions/

44. Toh, S. G., Ang, E., \& Devi, M. K. (2012). Systematic review on the relationship between the nursing shortage and job satisfaction, stress and burnout levels among nurses in oncology/haematology settings. International Journal of Evidence-Based Healthcare, 10(2), 126-141. doi:10.1111/j.1744-1609.2012.00271.x

45. Weydt, A. P. (2009). Defining, analyzing, and quantifying work complexity. Creative Nursing, 15(1), 7-13. doi:10.1891/1078-4535.15.1.7

46. Weyers, S., Peter, R., Boggild, H., Jeppesen, H., \& Siegrist, J. (2006). Psychosocial work stress in associated with poor self-rated health in Danish nurses: Atest of the effort-reward imbalance model. Scandinavian Journal of Caring Sciences, 20 (1), 26-34. doi:10.1111/j.14716712.2006.00376.x

\section{Contact Information}

Dr. Adambarage Chamaru De Alwis

University of Kelaniya, Sri Lanka

Faculty of Commerce and Management Studies

Department of Human Resource Management

Email: chamaru@kln.ac.lk; dealwisac@gmail.com 